\title{
Table of European and international material
}

\section{Primary material treaties and agreements}

Treaty Establishing the European

Community (Treaty of Rome) (1957)

art 59,60 ....

\section{Conventions}

Convention on Human Rights and

Biomedicine (Oviedo 4.IV.,

Spain 1997) $\quad$............. 2.14, 4.14, 17.1

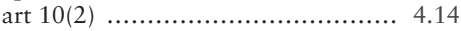

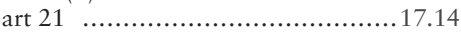

Additional Protocol concerning

Biomedical Research (Strasbourg,

2005)

art 9

$\operatorname{art} 23(3)$

15.13

European Convention on Human Rights and Fundamental Freedoms

(Strasbourg, 1950)

art 2

2.2, 2.7, 13.19, 14.7, $14.21,15.7,19.1,19.6$,

19.18

$\operatorname{art} 2(1)$ $19.6,19.18$

art 3 2.5, 2.7, 2.8, 19.1, $19.6,19.11,19.18$

art 5 $2.3,2.5,6.1,14.22$

art $5(1)$ $6.1,6.11,6.21$

$\operatorname{art} 5(1)(\mathrm{e})$ 2.9

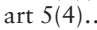
6.11 art 6 2.10 art $6(1)$ .. 2.3 art 7 7.22 art 8 2.2, 2.3, 2.7, 2.8, 2.10, 2.17, 4.2, 4.15, 11.10, 12.8, 12.9, $12.13,12.15,12.17,12.18$, 12.23, 13.1, 13.19, 14.10, 14.21, 15.18, 19.1, 19.6, 19.11, 19.18, 19.21 art $8(1) \ldots \ldots \ldots \ldots .2 .2,2.3,2.10,4.2,14.21$ art $8(2) \ldots \ldots \ldots \ldots . .2 .2,4.4,4.10,4.15,12.8$, $12.9,12.18,14.12,14.21$ art 9 $14.12,19.6$ art 10 $2.13,4.2,4.13$ art 12 $12.8,12.9,12.18$ art 14 $2.8,2.17,12.8,12.14$, $12.18,19.6,19.18$

First Protocol

arts $1-3$

Sixth Protocol

art 2

United Nations Convention on the

Rights of the Child.

\section{Secondary material}

\section{Declarations}

Declaration of Helsinki (World Medical Association, 1964) ...............15.5, 15.8

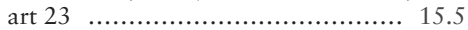

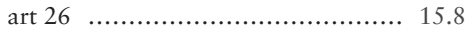

Declaration of Helsinki (World Medical Association, 2013) ............. 15.7, 15.13 art 33

\section{Directives}

Commission Directive 2005/28/EC (Good Clinical Practice Directive)

Council Directive 85/374/EEC (Products Liability Directive)

Council Directive 95/46/EC (Processing Personal Data) 4.17, 15.17, 15.18

Council Directive 2001/20/EC (Clinical Trials Directive) ...10.10, 15.1, 15.7, 15.12 art 5(a)....

Council Directive 2001/83/EC (Relating to Medicinal Products for Human Use) amended by Directives 2002/98/EC, 2003/63/EC/2004/24/EC and 2004/2/EC 10.11

Council Directive 2005//36/EC

(Recognition of Professional Qualifications) amended by Directive 2013/55/EU

Directive of the European Parliament and the Council on the Application of Patients' Rights in Cross Border Healthcare (2011) 2011/24/EU 


\section{Table of European and international material}

European Working Time Directive 93/103/EC

\section{Regulations}

EC Regulation 726/2004 art 83

EC Regulation 883/2004

EU Regulation on Medicinal Products for Paediatric Use Regulation (EC) $1901 / 2006$ art 41

EU Clinical Trials Regulation $536 / 2014$ $15.7,15.8,15.9,15.11$ art 28(2) 15.8

art 29(1) 15.8

art 29(2)(c) ............................ 15.8

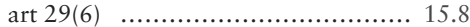

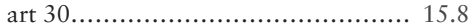

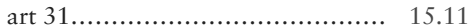

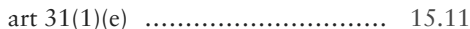

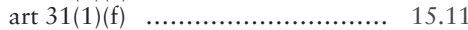

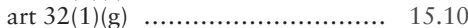

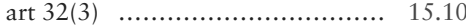

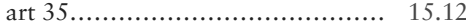

art 7 (3)........................... 15.14

Implementing Regulation 987/2009 (EC) 2.20 